\title{
Conceptual approach to the formation of innovation strategies of economic systems of the micro- and meso-level based on self- organization
}

\author{
Svetlana Uvarova*, Anatoly Bukreev and Vyacheslav Vlasenko \\ Voronezh State Technical University, 14, Moscow avenue, Voronezh, 394026, Russia
}

\begin{abstract}
In modern conditions, sustainable development of the economy of the country and regions inherently corresponds to the principle of innovation. The principle postulates the need to accelerate the development of innovation in the process of constant changes in a non-equilibrium economic system. The authors propose to ensure the accelerated development of innovations by implementing a scientifically based innovation strategy of regional enterprises. In this case, the concept of the development of strategies of the enterprise and the region, according to the authors, should be based on adapting the foresight methodology to the processes of self-organization of the system, including methodological tools for creating regional "points of innovation growth" taking into account the specifics of the region.
\end{abstract}

\section{Introduction}

In the modern conditions of unstable economic dynamics, issues of enhancing and optimizing innovation activity, the purpose of which is to create a trend of sustainable development of the economy, are priority and need a scientifically based decision that is aimed at the future.

Dynamic stability of the economy of the country and regions, ensuring not only the preservation at the existing level, but stable growth of indicators, can be achieved only with continuous interconnected updating of the production and technical base, organizational structure of management, economic bases of functioning based on innovations [1].

To stimulate innovation activity, it is necessary to implement a full cycle of organizational and economic (including institutional) changes aimed at solving major problems in a complex by not so much improving the production process as creating production and consumption trends, taking into account the trend of self-organization of the management system.

It should be noted that today, the innovative development of enterprises and the efficiency of their innovation activity are uneven both in the projection of economic activities, the size of enterprises, and in the projection of the regional economy [2]. The need to overcome the existing level of differentiation of innovative development leads to the feasibility of forming network forms of organizing interaction.

\footnotetext{
* Corresponding author: uvarova s.s@ mail.ru
} 
In spite of the significant contribution of scientists to the formation of the theory and methodology of strategic management of innovation activities of enterprises, modern realities form new requirements for economics to rethink a number of issues related to the need to ensure the effective innovative development of the economy of the country and regions.

Consequently, it is expedient to develop a concept and a methodological base for the formation of a strategy and promising innovation policy of enterprises, taking into account the network nature of changes in the system of interactions, as well as to plan relevant areas of innovative transformations already adopted at the state level to ensure their consistency and success, which is expedient to do within the foresight technology.

The development of an effective strategy and promising innovation policy of enterprises also requires the substantiation of key principles, modern methods of forecasting and assessment, adequate scientific and practical tools in order to overcome the differentiation in the level of innovative development of enterprises and improve the efficiency of innovation.

\section{Materials and Methods}

Self-organization of the management system of the enterprise and the region [3] occurs through periodic qualitative changes in the state of the system, which can has both evolutionary (slow change of parameters) and revolutionary (bifurcation change characterized by a change of attractors) character. The main reasons for the jump in the development of the economic management system at the meso- and micro- level, characterized by a qualitative change in management methods, were the following types of contradictions (in accordance with the topology of the contradictions of the self-organizing system [4]):

- the contradiction between the function and the purpose of the system (the function of the system is to create quality products; according to the results of the analysis carried out in [5], goal-setting at the level of the anthropocentric subsystem is aimed at maximizing profits, which led to negative structural shifts in the economy);

- the contradiction between the resource needs of the system and the possibility of their satisfaction (this contradiction is determined by structural disproportions of investment resources, expressed in the territorial differentiation of investment attractiveness);

- the contradiction between the changing quantity and the previous quality (this contradiction was expressed in the inconformity of the growth of volumes of investment and production with an outdated industrial base of industries and its organizational and economic structure);

- the contradiction between the aspiration of the system to establish a steady state and the means to achieve it (the economic system adapts to the environment and, as a result, becomes more responsive to fluctuations, the amplification of which causes the instability of the system followed by a jump);

- the contradiction between functioning and structure: in the evolutionary period, the change in the functioning processes is held back by slower rates of structural change; during the bifurcation period, a rapid abrupt change in the structure causes a lag in the rate of change in the functioning of the system.

The attainment of neighborhoods and the passage of a bifurcation point by a system often occurs as a result of a change in control parameters [6] or a control subsystem that takes the system to a new state. With regard to economic systems at the meso- and micro- levels, in our opinion, such a change was the transition to the implementation of the concept of the National Innovation System.

In this case, the time axis is divided into three segments (Figure 1) 


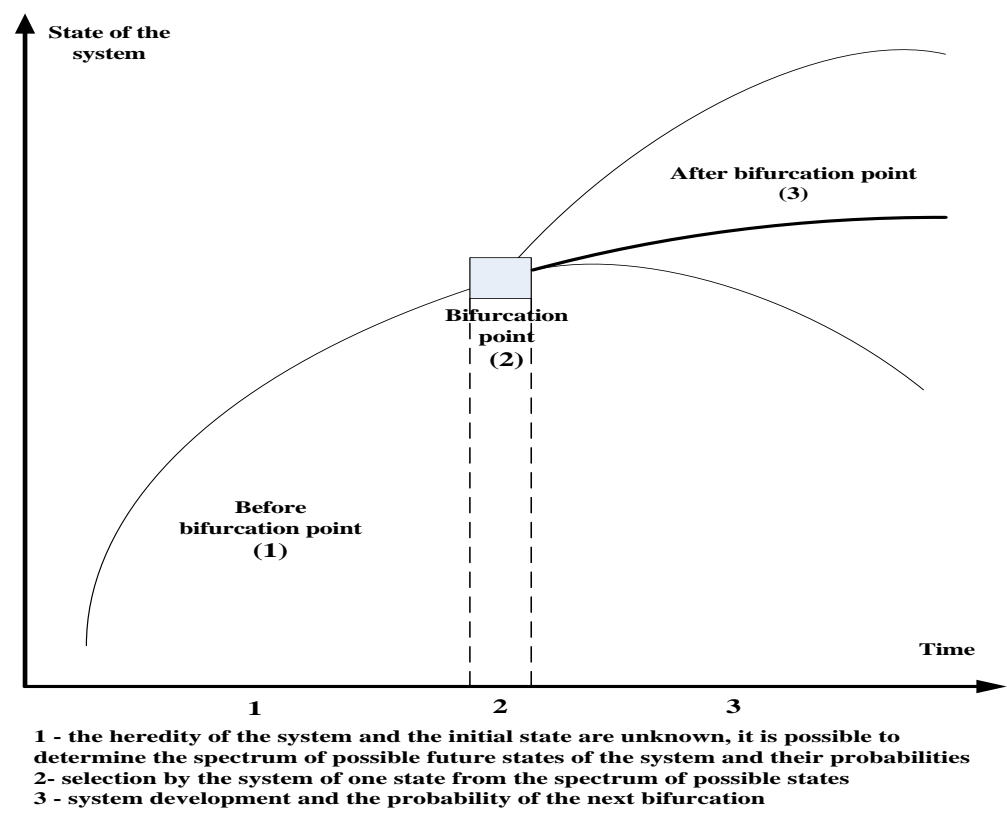

Fig. 1. The time axis of the system development (based on [6])

According to the findings of the mathematical theory of catastrophes, it is impossible to unambiguously predict the state into which the system will go after the bifurcation. However, each of the states of the spectrum of the bifurcation process can be characterized by a positive real number (less or equal to one) similar to the probability of the realization of this state after the bifurcation.

The system under the influence of external and internal fluctuations selects from the spectrum of possible states that path of further development that is consistent with the immanent properties of the system and its existing development experience (resonant excitation according to the theory of self-organization). According to the theory of selforganization, selection of the state of the system after the bifurcation is largely determined by the presence of "catalyst" in the system, stimulating the implementation of certain processes and generating the so-called loop of positive feedback of the further state of the system with previous experience.

Therefore, it is advisable to assess not so much the current state as the specificity and heredity of the system under study; identifying a multitude of system attractors, including target ones; forecasting the possible trajectories of the system development towards the selected attractors; development of initiated actions, "catalysts" of system fluctuations. This set of parameters can be implemented using the foresight methodology.

It is the approach to the enterprise and the region as to an open non-equilibrium system that makes it possible to effectively use foresight technology in the development of an innovation strategy and its elements, while at the same time preserving the probabilistic nature of the forecast and the activity nature of system engineering. The latter gives the right to modify the foresight technology from the standpoint of the design approach in order to adapt to the solution of applied problems.

\section{Results}

Considering the economic system of the micro- and meso-level as an open non-equilibrium 
system, which is characterized by self-organization in accordance with the provisions outlined above, the authors proposed the concept of forming an innovation strategy.

The concept is based on the initial postulate that the imperative of increasing the innovation activity and efficiency of the innovation process at the enterprise is the use of foresight technologies for the development of innovation activities, taking into account the selforganization of network interactions of the subjects on a regional institutional platform.

A schematic conceptual diagram of the formation of innovation strategies is presented in Figure 2.
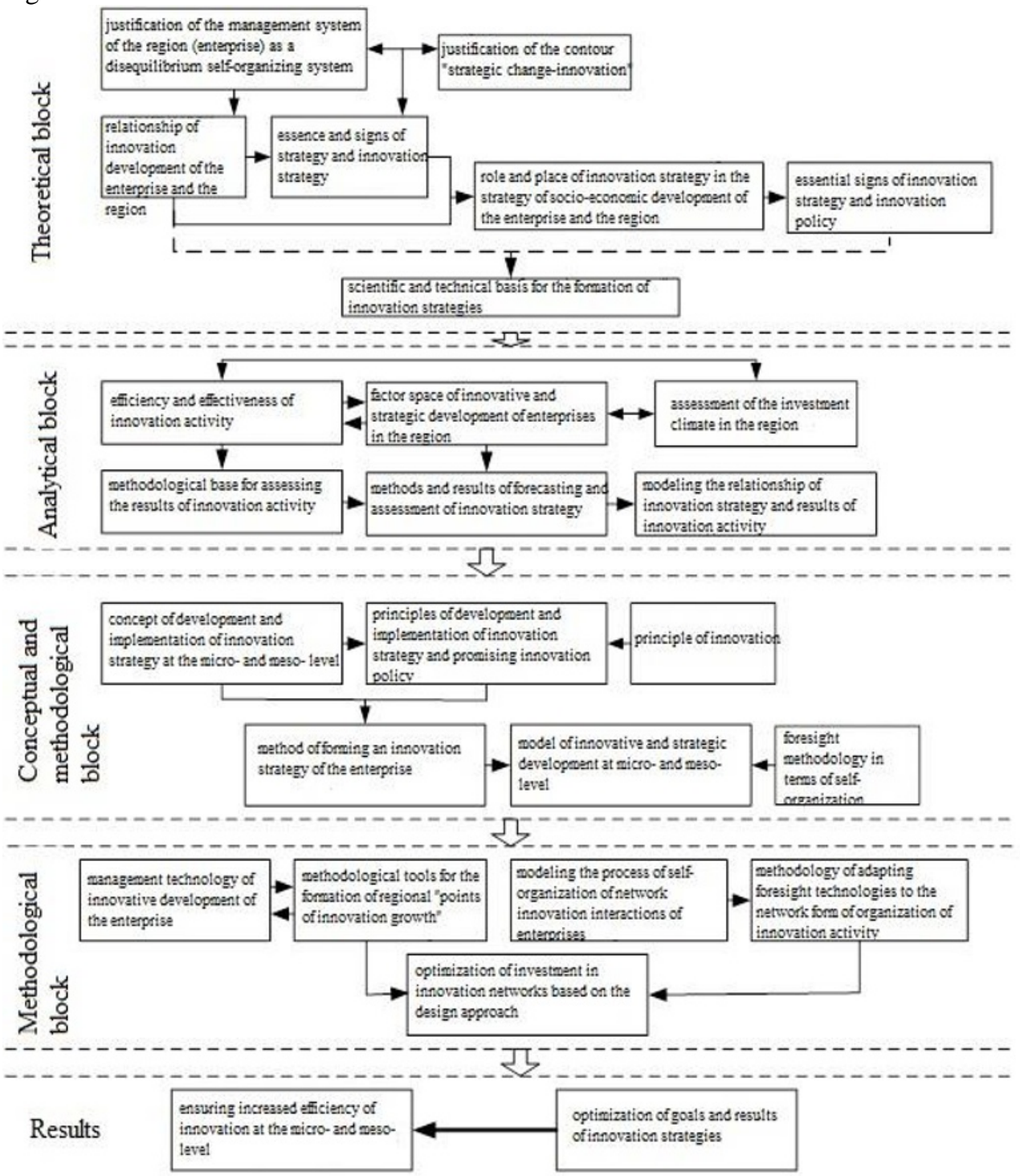

Fig. 2. A conceptual scheme for researching the problem of formation of innovation strategies at the micro- and meso- level of the economy

Therefore, the solution of the task has a complex multidimensional nature and must be based on a clear logical structure, starting with the refinement of the theoretical basis and ending with an empirical test of the reliability of the hypothesis.

As proved by the authors of [7], the process of forming an innovation strategy itself has a 
network form. Based on the high costs and high risk of innovation activity, the complexity of the innovation process, the successful implementation of innovations requires the formation of an innovation network [7]. Innovation process networking leads to the emergence of not only the cumulative but also the synergistic effect of the interaction of enterprises. Based on the network nature of the innovation process and network interactions of participants in innovation activities, we consider it expedient to use the mathematical apparatus of graph theory in predicting innovation strategy and modeling network effects.

As the analysis showed, there is a sufficient degree of correlation between the innovation strategy of the enterprise and the development strategies of the macro- and meso-level. Moreover, taking into account the specifics of the network innovation process, the communication nature of the network, the most important aspect of the formation of an innovation strategy for the enterprise is to optimize interaction with the strategy of the region.

The importance of forming an actual regional strategy is confirmed by the presence of evident regional differentiation according to the criteria of the level of investment attractiveness of the regions $[8,9]$. The basis of the investment potential consists of natural resources. However, in the conditions of transition to an innovative development path, the financial, social and political stability of the region acquires great importance. Thus, the coefficient of pair correlation between the indicator of the investment potential of the region and budget revenues, the GRP and the balanced financial result of the organizations of the region was $0.9,0.91$ and 0.89 , respectively.

Nowadays, when competition between regions for the attracted volume of investment is high, measures are being developed that increase the investment attractiveness.

The level of innovation activity of regional enterprises and the dynamics of innovative development of the region are part of the key factors of the innovation attractiveness of the region (Figure 3).

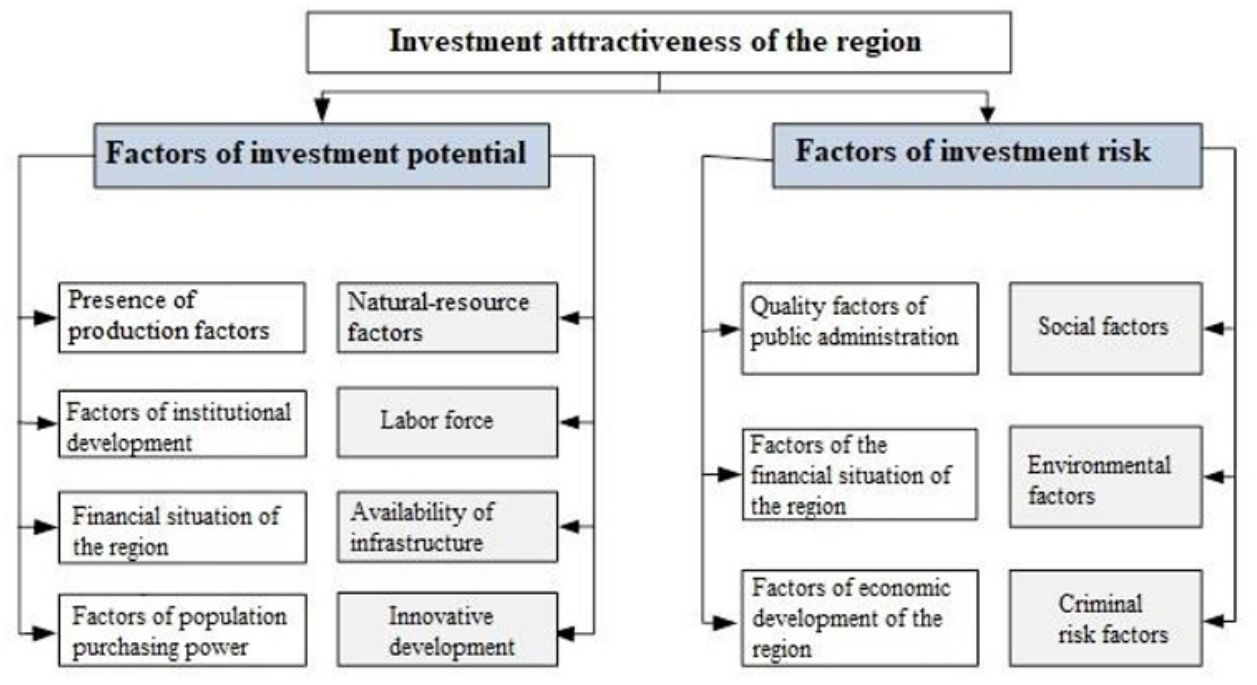

Fig. 3. Clustering of factors of innovation attractiveness of the region

Among such measures, it is necessary to emphasize the creation of territories of advanced socio-economic development (TASED) and the development of industrial parks. We have proven that such an effective state zoning policy contributes to enhancing the diffusion of innovations both in the horizontal (within the region) and in the vertical (between industries) projections by creating "points of innovation growth" in accordance with the "neighborhood effect" by T. Hagerstrand. Schematically, this thesis is depicted in Fig.4. 


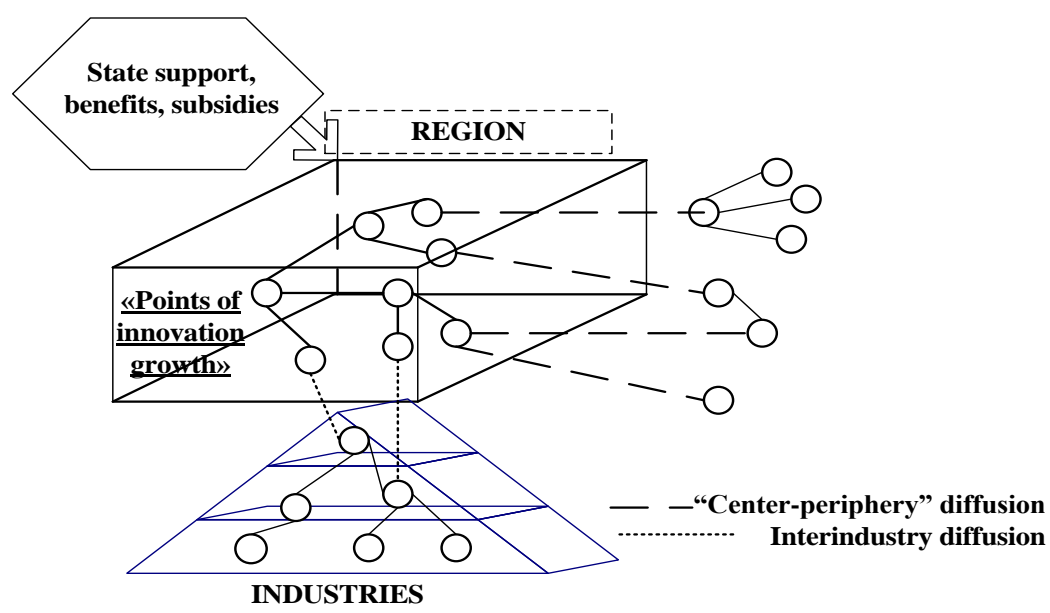

Fig. 4. Network innovation interaction of enterprises and the effect of the "point of innovation growth"

In order to assess the effect of creating "points of innovation growth", we proposed a modified methodology for rating the investment attractiveness of regions.

At the first stage, statistically significant criteria for assessing the investment attractiveness of the region are identified using the formula:

$$
r_{p}=\frac{\operatorname{cov} x y}{\delta_{x} * \delta_{y}}>0,6
$$

where $r_{p}$ - the correlation coefficient, cov - the covariance, $\delta$ - the standard deviation

This assessment procedure can be performed twice: first, by assessing the set of criteria of various rating systems in order to determine the set of the most widely sought-after criteria; secondly, by defining an additional set of statistical indicators of the region for inclusion in the rating system along with already used ones. In addition, taking into account the purpose of the assessment, a representative sampling by indicators of the level of innovative development of the region and the results of innovative activities of enterprises should be included in the consideration.

Next, the key criteria are determined, which form the ranks of the regions according to the degree of investment attractiveness according to the formula:

$$
\rho_{F}=1-\frac{6 * \sum d^{2}}{n *\left(n^{2}-1\right)}>0,7
$$

where $\rho_{F}$ - rank correlation coefficient, d - rank difference.

The selection of the most significant rating criteria is based on multiple choice models for econometric analysis. In this case, the results of the calculation of factor loads characterize the share of each factor sign in the structure of region ranking factors.

At the third stage, the hierarchical method forms (clusters) the selected set of factors for rating construction. With representative statistics on rating results, a set of factors can be formed by determining the factor load. However, when constructing new ratings or optimizing existing ones, we consider it appropriate to use the formula:

$$
K_{\eta}([i, j], k)=\left[\frac{\left(n_{i} K(i, k)^{\eta}+\left(n_{j} K(j, k)^{\eta}\right)\right.}{n_{i}+n_{j}}\right]^{\frac{1}{\eta}},-\infty \leqslant \eta \leqslant+\infty
$$


where $k-$ a cluster of factors for which a similarity search for a group of factors $\mathrm{i}$ and $\mathrm{j}$ is conducted; $n_{i}$ - the number of elements in the cluster $i ; n_{j}$ - the number of elements in the cluster $j$.

Next, the regions are clusterized by a set of selected factors using the K-means method:

$$
D_{(i, k)}=\sqrt{\frac{1}{M}} \sum_{j=1}^{M}\left(F_{i j}-\bar{F}_{j}^{k}\right)^{2},
$$

where $F_{i j}$ - value of factor $\mathrm{i}$ and $\mathrm{j}, \bar{F}_{j}^{k}$ - average value of factor $\mathrm{j}$ and cluster $\mathrm{k}, \mathrm{M}$ - the number of factors.

Based on the results of clustering, an assessment of the efficiency of the corresponding managerial decisions aimed at forming "points of innovation growth" for each of the regions is made.

\section{Discussions}

Based on the results of clustering, the investment attractiveness of Russian regions, taking into account the characteristics of innovative development, is uneven. Therefore, the proposed concept is also relevant in relation to the method of creating "points of innovation growth". When forming an innovation strategy of the economic system of the micro-level, which allows significantly improving its activities, it is necessary to provide stimulation of innovation processes through the introduction of modern methods of strategic management of regional zoning and the creation of "points of innovation growth" that take into account the institutional, economic, organizational, informational, analytical, and regional aspects of management.

Foresight technologies allow taking into account the multiplicity of stakeholders of the innovative development of enterprises, which is especially important when modeling "points of innovative growth". In general, the algorithm of foresight technology for developing an innovation strategy of the enterprise is presented in Fig. 5.

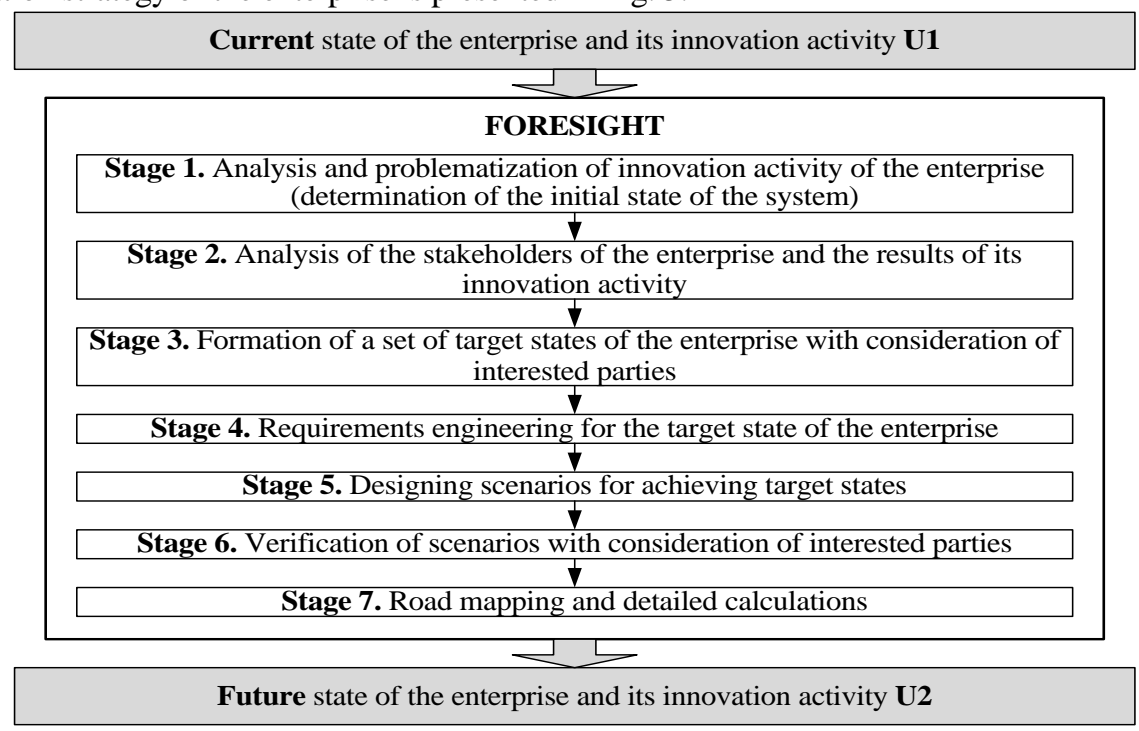

Fig. 5. Algorithm of foresight technology for the development of innovation strategy of the enterprise 
Such an optimization of the regional zoning policy mechanism accelerates the diffusion of innovations both across the country and in the industrial context, which will provide a synergistic effect of innovation activity.

\section{Conclusion}

All of these aspects must be taken into account in the formation of innovation strategies for not only enterprises but also for industries and regions.

In general, we consider it expedient to build an innovation strategy based on foresight technology. This thesis is based not only on the systematization of methodological foundations of foresight and its implementation in the strategic planning but also on the need based on the essence of the concept of innovation strategy, system design of research object (enterprise, region) in accordance with its target focus and the factor space of innovative and strategic development. In this context, system design and transformation of the object are elements of innovation policy. Foresight also can be implemented as a series of interrelated projects that will allow effective implementation of the identified fractality between innovation strategies of the micro- and meso-level of the economy.

Observance of the principle of innovation along with the assessment, monitoring and targeted changes of the investment climate of the regions contribute to solving the problem of increasing the power of the economic system of the country as a whole.

\section{References}

1. Belyaeva S., Voronov D., Erypalov S. MATEC Web of Conferences 106, 08033 (2017).

2. Gumba, K., Belyaeva, S. IOP Conference Series: Earth and Environmental Science, (2017)

3. Kulakov K., Belyaeva S., Belyantseva O., Gamisoniya A. MATEC Web of Conferences. 01118. (2018)

4. Uvarova S., Myshovskaya L., Kulakov K. MATEC Web of Conferences. 01119. (2018)

5. Uvarova S., Vlasenko V., Bukreev A., Myshovskaya L., Kuzina O. E3S Web of Conferences. 03022. (2018)

6. Basina, G. I. Sinergetika. Vselennaya rezonansov, SPb. : Norma, 2008. - $144 \mathrm{~s}$.

7. Nezhnikova T., Papelniuk O., Gorokhova A. Russia-China energy dialogue: research of the most promising energy areas for interrelation. International Journal of Energy Economics and Policy. № 8(1). 203-211. (2018)

8. Bukreev A., Vasilyeva O., Vlasenko V., Sizova E. MATEC Web of Conferences 106, 08034 (2017).

9. Kankhva V., E3S Web of Conferences 33, 01036 https://doi.org/10.1051/e3sconf/20183301036 